\title{
EFICIÊNCIA TRIBUTÁRIA MUNICIPAL E SEUS DETERMINANTES: UMA ABORDAGEM SEMI-PARAMÉTRICA VIA REGRESSÃO BETA ${ }^{1}$
}

\author{
Luiz Henrique dos Santos Fernandes ${ }^{\mathrm{a} *}$, Maria da Conceição Sampaio de Sousa ${ }^{\mathrm{b}}$

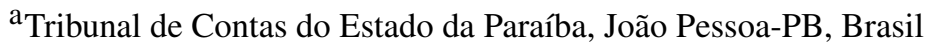 \\ ${ }^{\mathrm{b}}$ Departamento de Economia \\ Universidade Federal da Paraíba - UFPB, João Pessoa-PB, Brasil
}

Recebido 01/11/2018, aceito 10/12/2018

\begin{abstract}
RESUMO
A presente pesquisa mensura a eficiência técnica tributária de municípios do Estado da Paraíba e avalia seus determinantes por meio de abordagem semi-paramétrica em dois estágios. No primeiro estágio foram obtidos escores de eficiência por meio de MDEA (Multiple Data Envelopment Analysis). No segundo estágio utilizou-se modelo de regressão beta para estimar a influência de variáveis ambientais na eficiência tributária dos governos locais. Os principais resultados mostram que a eficiência tributária tem relação direta com a população dos municípios, com o grau de autossuficiência financeira, com o valor adicionado ao PIB pelo setor industrial e com o índice de transparência na gestão. Por outro lado, contribuem para a redução da eficiência tributária fatores como a dependência de transferências de outros entes governamentais e um alto índice de concentração de Herfindahl aplicado aos tributos de competência dos municípios.
\end{abstract}

Palavras-chave: Eficiência técnica tributária, MDEA, Modelo de regressão beta.

\begin{abstract}
The present study measures the technical tax efficiency of municipalities of the State of Paraíba and evaluates its determinants through a two-stage semi-parametric approach. In the first stage efficiency scores were obtained with the use of MDEA (Multiple Data Envelopment Analysis). In the second stage a beta regression model was used to estimate the influence of environmental variables on the tax efficiency of local governments. The main results showed that tax efficiency is directly related with the population of the municipalities, degree of financial self-sufficiency, value added to GDP by the industrial sector and the management transparency index. On the other hand, contributed to reduce tax efficiency factors such as dependence on grants from other governmental entities and a high Herfindahl concentration index applied to the municipal taxes.
\end{abstract}

Keywords: Technical tax efficiency, MDEA, Beta regression model.

\footnotetext{
* Autor para correspondência. E-mail: lfernandes@tce.pb.gov.br

DOI: 10.4322/PODes.2018.011
}

${ }^{1}$ Todos os autores assumem a responsabilidade pelo conteúdo do artigo. 


\section{Introdução}

A eficiência na prestação de serviços públicos é um tema que vem adquirindo extrema relevância no atual contexto político-econômico do Brasil e do mundo. O aumento na demanda por bens públicos e a limitação de recursos financeiros têm refletido diretamente na qualidade dos serviços prestados e nos resultados alcançados, acarretando inúmeras pesquisas sobre mensuração de eficiência no setor público. Um conceito amplo de eficiência, sob a ótica da teoria econômica, está relacionado à obtenção do maior benefício possível com uma quantidade mínima de recursos. $\mathrm{Na}$ economia do setor público, eficiência refere-se ao nível agregado de atividade econômica. A coordenação entre arrecadação de receitas e provisão de serviços para funcionamento eficiente da atividade econômica provê um papel natural para o setor público (Hindriks e Myles, 2013). Eficiência, no contexto deste trabalho, está relacionada com o conceito de eficiência técnica definido na teoria da produção, qual seja, a obtenção do máximo de produto com o mínimo de insumos.

Segundo Hindriks e Myles (2013), um dos objetivos da descentralização político-administrativa é garantir a eficiência na arrecadação de tributos e na provisão de bens ou serviços públicos pelos diversos níveis de governo. O modelo de descentralização definido na Constituição Federal de 1988 atribuiu competências específicas para cada ente quanto à prestação de serviços públicos, bem como em relação aos tributos de competência de cada esfera de governo. União, estados e municípios têm o dever de instituir e arrecadar os tributos de sua competência. A União e os estados têm, ainda, o dever de transferir parcelas de suas receitas próprias para esferas de governo inferiores, conforme prescrito no texto constitucional. A estrutura do sistema tributário demanda recursos humanos, materiais e financeiros para consecução de suas atividades, constituindo, desse modo, uma espécie de serviço público, cujo produto é a efetiva arrecadação dos tributos de competência do ente. A busca pela eficiência não se limita, portanto, ao provimento dos serviços públicos.

Por outro lado, o processo de descentralização promovido pela Constituição Federal de 1988, que transformou os municípios em entes politicamente autônomos, trouxe um aumento na responsabilidade destes no provimento de bens e serviços públicos, com uma maior descentralização nas áreas de educação e saúde. Esse processo pode ter acentuado as desigualdades regionais, pois muitos municípios são incapazes de dispor de autonomia financeira, devido à concentração da base produtiva no Brasil e às diferenças socioeconômicas históricas. Para compensar essas distorções, foram inseridos na Carta Magna dispositivos que determinam a transferência de recursos para os governos locais, por meio da repartição de receitas da União e dos estados, aumentando a dependência de muitos municípios em relação a esses recursos, que em muitos casos constituem parcela considerável da receita destes entes. Esse processo pode ter gerado uma diminuição no esforço fiscal, não obstante suas limitadas bases tributárias, com consequente redução das receitas próprias municipais.

O objetivo deste trabalho é mensurar a eficiência técnica tributária de municípios do Estado da Paraíba e avaliar seus determinantes, por meio de abordagem semi-paramétrica em dois estágios. Na Seção 2 apresentamos uma revisão da literatura relacionada ao estudo da eficiência técnica tributária e utilização da regressão beta. Na Seção 3 será abordada a metodologia utilizada nesta pesquisa, com maior detalhamento do MDEA (Multiple Data Envelopment Analysis), do modelo de regressão beta e das variáveis empregadas. Na Seção 4 serão apresentados os resultados considerando regressão linear estimada pelo método dos mínimos quadrados ordinários e regressão beta. Na Seção 5 serão expostas as considerações finais sobre o trabalho.

\section{Estudos Anteriores Relacionados}

Pioneiros no estudo do esforço fiscal dos municípios brasileiros, Orair e Alencar (2010) estimaram um índice de esforço fiscal obtido pela comparação entre a arrecadação tributária efetiva dos municípios e a arrecadação estimada por meio de uma regressão linear que emprega o método dos mínimos quadrados ordinários cross section, controlada por fatores econômicos, ins- 
titucionais e de localização, que explicariam a receita própria dos municípios. Foram utilizados dados dos municípios brasileiros do período de 2000 a 2009. Os resultados indicaram que $41 \%$ apresentaram, em 2007, um grau de esforço fiscal abaixo da média. Além disso, os testes de significância estatística confirmaram a hipótese de que as transferências têm uma influência negativa sobre a arrecadação própria. Por fim, a análise da evolução das receitas municipais no período em estudo mostrou que houve incremento importante na arrecadação de ISS (Imposto sobre serviços de qualquer natureza) dos municípios e queda relativa na arrecadação de IPTU (Imposto sobre propriedade predial e territorial urbana).

Uma abordagem não-paramétrica foi utilizada por Campello (2003), aplicando DEA (Data Envelopment Analysis) para avaliar a eficiência na gestão dos municípios do Estado de São Paulo. $\mathrm{O}$ autor, em sua tese de doutorado, analisa as mudanças causadas pela Constituição Federal de 1988 em relação ao perfil tributário dos entes federativos e das alterações na agenda governamental. Traça, ainda, um panorama das influências externas e internas sobre a economia, que levaram os municípios a assumirem responsabilidades que não estavam claramente definidas na agenda, ocasionando o que a literatura denomina de hiato de recursos. Sua pesquisa analisou a existência e dimensionamento desse hiato, na perspectiva da gestão municipal, buscando uma aproximação dos conceitos de eficiência de exploração, que se refere à capacidade de explorar as bases tributárias; e de eficiência de transformação, que se refere à capacidade de um município conseguir transformar os recursos de que dispõe em qualidade de vida. Os resultados mostraram que os municípios possuem baixa eficiência na exploração das bases tributárias e altos valores de eficiência na transformação. $\mathrm{O}$ autor conclui, ainda, que a ampliação da qualidade de vida nos municípios passa pela alteração do sistema de transferências, em função dos baixos valores de receitas próprias que os municípios podem atingir.

Gasparini e Melo (2004) utilizaram métodos não-paramétricos para avaliar o processo de repartição de recursos públicos operado pelo FPM (Fundo de Participação dos Municípios), de forma a verificar em que medida tem atendido ao art. 161, inciso II da Constituição Federal, que dispõe sobre os critérios de rateio de impostos arrecadados pela União. Foi empregado DEA para avaliação do atual modelo de repasse do FPM, partindo do pressuposto de que os níveis ótimos de transferência deveriam corresponder à diferença entre os custos mínimos para a prestação de serviços públicos equitativos e o potencial de receitas locais. Foi avaliada, também, a eficiência da arrecadação tributária dos municípios brasileiros, no intuito de verificar se as transferências corresponderam à diferença entre os custos equitativos ótimos e a capacidade de arrecadação local. $\mathrm{O}$ estudo foi aplicado a dois estados brasileiros de realidades distintas, Pernambuco e Rio Grande do Sul, com dados do ano de 2000. Os resultados destacaram a forte necessidade de complementação de verbas pelos municípios para prestarem os serviços demandados localmente e a necessidade de revisão dos critérios de rateio das verbas oriundas do FPM.

Métodos semi-paramétricos em dois estágios foram aplicados por Sousa et al. (2012) na mensuração da eficiência tributária de uma amostra de municípios brasileiros. No primeiro estágio, foram calculados os escores de eficiência com uso de DEA para estimar uma fronteira de produção. Foram considerados como insumos as despesas administrativas e o número de servidores, e como produtos as receitas arrecadadas e os cadastros tributários. Foi aplicada uma técnica de detecção e remoção de outliers chamada Jackstrap, desenvolvida por Ribeiro e Sousa (2004). No segundo estágio, foi utilizada regressão quantílica para estudo dos determinantes dos índices calculados no primeiro estágio, considerando base tributária, estrutura administrativa, composição do PIB, variáveis fiscais, dentre outras. Os resultados indicaram a existência de um padrão regional de eficiência tributária que, quando comparado aos municípios do Sudeste, favorecem os municípios do Centro-Oeste e Sul, em detrimento daqueles das regiões Norte e Nordeste. Sugerem, ainda, um papel determinante da base tributária sobre a eficiência dos municípios, principalmente quando relacionada ao setor industrial. Os resultados sugeriram, também, que uma diversificação tributária pode se configurar como estratégia eficaz para incrementar a eficiência tributária municipal. Importante destacar, também, que os resultados indicaram influência negativa das transferências 
na arrecadação de tributos e na alocação eficiente de recursos.

O uso da regressão beta no modelo semi-paramétrico em dois estágios para avaliação de eficiência é uma abordagem recente. Cribari-Neto e Pereira (2013) utilizaram um modelo baseado em regressão beta com efeitos espaciais na avaliação da eficiência das administrações municipais no Estado de São Paulo. Foram utilizados modelos de regressão beta e beta inflacionado, este último apresentando melhor qualidade no ajuste. Os resultados indicaram que municípios mais urbanizados e aqueles cujos prefeitos eram filiados a determinados partidos tendem a apresentar maior grau de eficiência administrativa. Os autores destacaram, ainda, que o recebimento de royalties exerce um efeito médio negativo sobre as eficiências das demais municipalidades brasileiras, mas que esse efeito inexiste em São Paulo.

Pereira et al. (2014) utilizaram um modelo baseado em regressão beta para avaliar e comparar os desempenhos das regiões brasileiras no que se refere ao gerenciamento de recursos públicos. Foram utilizados escores de eficiência obtidos no trabalho desenvolvido por Sousa e Stosic (2005), que estimaram índices de eficiência por meio de DEA. No segundo estágio os escores de eficiência foram utilizados como variável dependente em um modelo de regressão beta inflacionado, para análise dos determinantes da eficiência administrativa dos municípios localizados nas regiões estudadas. Os resultados indicaram que, com exceção da região Norte, municípios com maiores taxas de urbanização tendem a ser mais eficientes. Em contrapartida, ao contrário do esperado, os municípios das regiões Sudeste e Nordeste que recebem mais de $10 \%$ da sua receita a título de royalties, bem como os municípios das regiões Sudeste, Nordeste e Centro-Oeste que participam de consórcios intermunicipais, tendem a ser menos eficientes. Os resultados sugeriram, ainda, que o maior percentual de municípios plenamente eficientes encontrava-se na região Sudeste.

\section{Metodologia}

\subsection{Estratégia Empírica: O Modelo MDEA-Beta}

O modelo empírico selecionado para a presente pesquisa utiliza abordagem semi-paramétrica em dois estágios para mensuração da eficiência técnica tributária de municípios do Estado da Paraíba. Foi selecionada uma amostra composta por 210 municípios. O estudo aborda, por meio de análise de regressão, a influência de variáveis socioeconômicas, fiscais, operacionais e geográficas sobre os escores de eficiência obtidos. No primeiro estágio, a eficiência técnica tributária foi calculada por meio de MDEA (Multiple Data Envelopment Analysis). No segundo estágio, os escores de eficiência foram utilizados como variável resposta em um modelo de regressão beta. Foi utilizado, também, um modelo de regressão linear estimado pelo método dos mínimos quadrados ordinários. Nas subseções seguintes, serão detalhadas as técnicas empregadas neste trabalho.

De acordo com Sousa (2011), muitos autores consideram que os insumos e produtos do primeiro estágio são correlacionados com as variáveis ambientais utilizadas no segundo estágio. Essa corrente, chamada de convencionalista, assevera que a interdependência entre os escores DEA violaria a suposição de que as variáveis dependentes não são correlacionadas, exigida pela análise de regressão. Uma solução encontrada foi o uso de técnicas de bootstrap para corrigir os estimadores e melhorar a inferência, como o método proposto por Simar e Wilson (2007).

Por outro lado, autores ligados a uma corrente com abordagem instrumentalista, como McDonald (2009), consideram que os escores de eficiência DEA devem ser vistos como medidas descritivas do desempenho relativo das DMU's (Decision Making Units). Nessa interpretação, a fronteira de eficiência corresponde ao resultado das melhores práticas observadas. A visão convencionalista considera esses escores como estimadores da eficiência verdadeira das DMU's. O uso da abordagem instrumentalista permitiria, portanto, solucionar o viés convencionalista, pois os escores de eficiência gerados pelo DEA não seriam exemplos de dados censurados ou corner data, e sim de dados fracionários ou proporcionais. Com isso, seriam tratados como qualquer outra variável dependente (McDonald, 2009). No presente trabalho, foi aplicada a abordagem instrumentalista. 


\subsubsection{DEA (Data Envelopment Analysis)}

A Análise Envoltória de Dados foi introduzida por meio do trabalho seminal de Charnes et al. (1978), inspirados no conceito de eficiência técnica desenvolvido por Farrell (1957). Conhecida também como DEA, do inglês Data Envelopment Analysis, esta abordagem identifica as melhores práticas de DMU's (Decision Making Units) similares, com base em um modelo de programação linear em que a razão entre outputs e inputs deve ser maximizada. O modelo de Charnes et al. (1978) trabalha com retornos constantes de escala e ficou conhecido como DEA-CCR. Banker et al. (1984) desenvolveram uma proposta que incorpora retornos variáveis de escala, chamada de DEA-BCC. A abordagem do presente trabalho baseia-se no modelo DEA-CCR. Apresentamos a seguir a forma fracionária do modelo DEA-CCR. As variáveis $x_{i j}$ e $y_{r j}$ correspondem aos inputs e outputs das DMU's, respectivamente, enquanto $v_{i}$ e $u_{r}$ são os pesos associados. A constante $\epsilon$ é uma pequena medida não-Arquimediana.

$$
\begin{array}{r}
\max h_{0}=\frac{\sum_{r=1}^{s} u_{r} y_{r o}}{\sum_{i=1}^{m} v_{i} x_{i o}} \\
\text { s.a. } \frac{\sum_{r=1}^{s} u_{r} y_{r j}}{\sum_{i=1}^{m} v_{i} x_{i j}} \leq 1 \forall j \\
u_{r}, v_{i} \geq \epsilon \forall i, r
\end{array}
$$

Este modelo pode ser linearizado, com o objetivo de alcançar uma melhor eficiência computacional. Apresentamos abaixo o modelo DEA-CCR em sua forma linear. O modelo MDEA (Multiple Data Envelopment Analysis) apresentado neste artigo é fundamentado nesta formulação.

$$
\begin{array}{r}
\max z_{0}=\sum_{r=1}^{s} u_{r} y_{r o} \\
\text { s.a. } \sum_{r=1}^{s} u_{r} y_{r j}-\sum_{i=1}^{m} v_{i} x_{i j} \leq 0 \forall j \\
\sum_{i=1}^{m} v_{i} x_{i o}=1 \\
u_{r}, v_{i} \geq 0 \forall i, r
\end{array}
$$

\subsubsection{MDEA (Multiple Data Envelopment Analysis)}

O MDEA é uma extensão da Análise Envoltória de Dados convencional, desenvolvido por Stosic e Fittipaldi (2007), e seu método é constituído por múltiplas execuções DEA para diferentes possíveis escolhas de subconjuntos de variáveis de entrada e saída (inputs e outputs). Trata-se de uma variação do DEA pouco explorada ainda. Segundo os autores, o procedimento é recomendado para situações em que um grande número de variáveis de entrada e saída deve ser levado em conta, ou o número de DMU's seja relativamente pequeno, evitando, com isso, um efeito comum chamado de "maldição da dimensionalidade". Isto ocorre quando o número de DMU's é pequeno em relação ao número de inputs e de outputs, fazendo com que muitas DMU's obtenham eficiência de valor unitária, situando-as na fronteira. Com isso, reduz-se o poder de discriminação do DEA. Para lidar com este problema, o método proposto investe esforço computacional considerável para processar um grande número de inputs e outputs, e suas respectivas combinações. Os itens a seguir apresentam a sequência de passos do algoritmo do MDEA, conforme detalhado por Stosic e Fittipaldi (2007):

1. Identificam-se os maiores conjuntos de $N$ entradas e $M$ saídas consideradas relevantes para a pesquisa; 
2. Em seguida, escolhem-se, sucessivamente, todos os subconjuntos diferentes de $n \in(1,2, \ldots$, $N)$ entradas e $m \in(1,2, \ldots, M)$ saídas;

3. O DEA é aplicado, então, a cada combinação de subconjuntos de entradas e de saídas para todas as DMU's;

4. Como existem $\left(2^{N}-1\right)$ possíveis escolhas para as entradas e $\left(2^{M}-1\right)$ possíveis escolhas para as saídas, teremos, para cada DMU, um total de $N_{c}=\left(2^{N}-1\right)\left(2^{M}-1\right)$ combinações possíveis;

5. Ao final, cada DMU terá $N_{c}$ escores de eficiência, o que representa a forma mais justa de avaliação em relação às outras, abrangendo todos os possíveis contextos de entradas e saídas;

6. Com os resultados obtidos, constroem-se as distribuições de frequência, obtendo-se a média (ou outra estatística escolhida pelo pesquisador) para cada DMU.

Na presente pesquisa, o MDEA foi implementado na linguagem $R$, conforme ilustrado no Algoritmo 1. A estratégia adotada iniciou-se com o emprego de um algoritmo de enumeração de subconjuntos aplicado aos conjuntos de inputs e de outputs, seguindo a lógica para subsequências apresentada por Feofiloff (2009). Segundo o autor, uma subsequência é o que sobra quando alguns elementos de uma sequência são apagados. Mais precisamente, uma subsequência de $a[1 . . n]$ é qualquer sequência $s[1 . . k]$ tal que $s[1]=a\left[i_{1}\right], s[2]=a\left[i_{2}\right], \ldots, s[k]=a\left[i_{k}\right]$ para alguma sequência $1 \leq i_{1}<i_{2}<\ldots<i_{k} \leq n$ de índices. Em particular, uma subsequência de $1 . . n$ é qualquer sequência subs[1..k] tal que $1 \leq \operatorname{subs}[1]<\operatorname{subs}[2]<\ldots<\operatorname{subs}[k] \leq n$. Essa enumeração foi realizada em ordem lexicográfica e resultou em subconjuntos de índices das colunas da base de dados. Cada subconjunto foi armazenado em um vetor. Os vetores resultantes foram armazenados em uma estrutura de dados do $\mathrm{R}$ chamada lista. As listas nesta linguagem permitem armazenar estruturas de dados de naturezas distintas. No presente caso, vetores de diversos comprimentos.

Em seguida, foram utilizados dois laços de repetição for aninhados para o cálculo dos escores de eficiência DEA para cada combinação de subconjuntos de inputs e outputs. Os resultados foram armazenados em um data frame, ou seja, em uma tabela de uma base de dados em que cada linha corresponde a um registro. Os escores de eficiência DEA foram calculados por meio do pacote benchmarking, do R. Foi utilizado, ainda, o pacote dplyr para seleção das colunas da base de dados que comporiam os subconjuntos de inputs e de outputs, com base nos índices das listas. A opção de utilização do MDEA nesta pesquisa tem relação com modelo de regressão beta escolhido. Por ser resultado de uma estatística, a probabilidade de obtenção de escore de eficiência MDEA igual à 1 é pequena, possibilitando o emprego do modelo de regressão beta padrão, em que a variável dependente deve situar-se no intervalo aberto $(0,1)$. Do contrário, teríamos que utilizar modelos de regressão beta mais complexos, como o modelo de regressão beta inflacionado, Bayer (2011).

\subsubsection{O Modelo de Regressão Beta}

Os modelos de regressão beta são comumente usados para trabalhar com variáveis dependentes que assumem valores no intervalo $(0,1)$, como taxas e proporções, tendo em vista a flexibilidade em relação à forma de sua densidade. O modelo é baseado na função de densidade da distribuição beta, em termos de dois parâmetros que indexam sua distribuição. A função de densidade beta é expressa por:

$$
f(y ; p, q)=\frac{\Gamma(p+q)}{\Gamma(p) \Gamma(q)} y^{p-1}(1-y)^{q-1}, 0<y<1,
$$




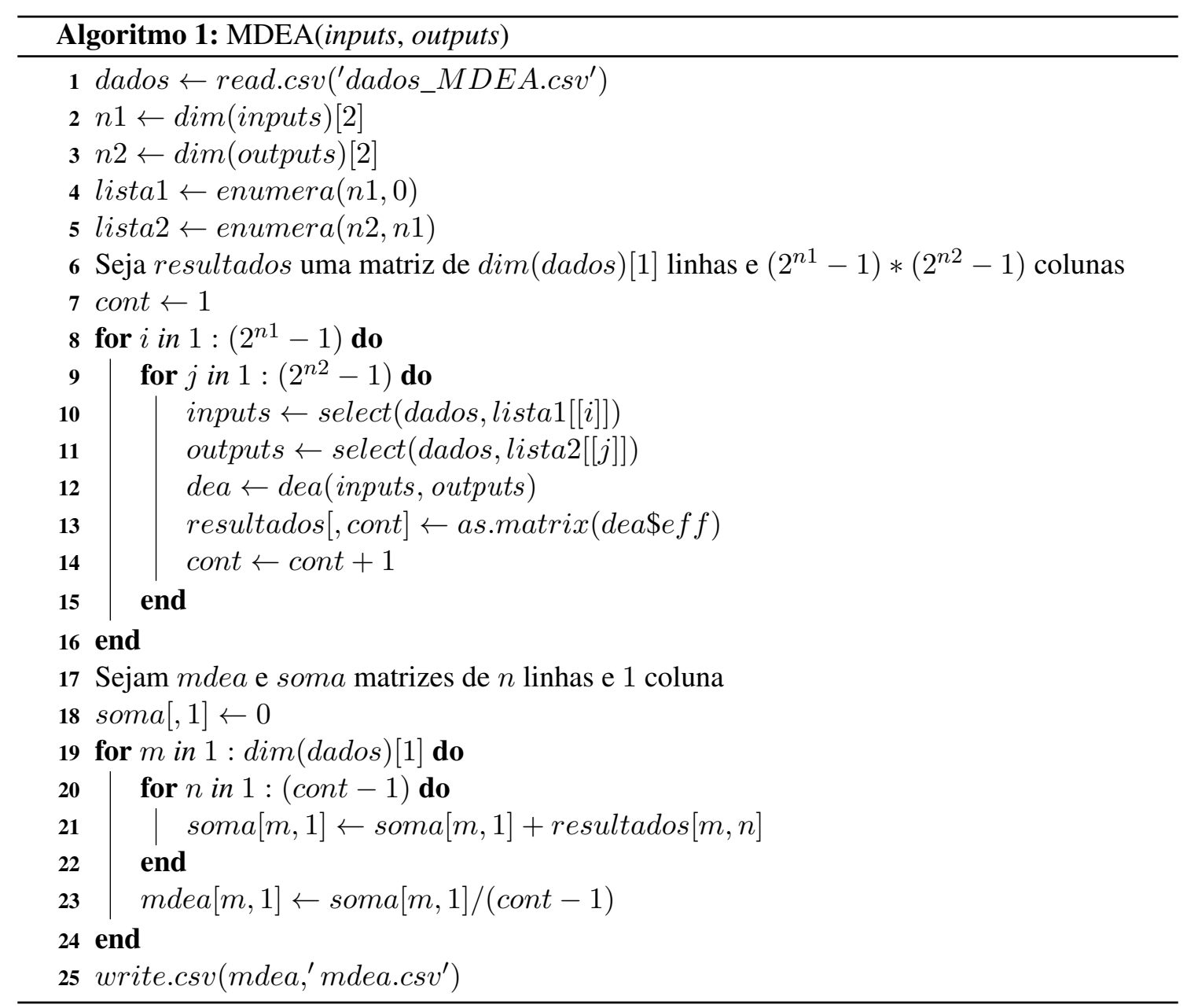

onde $p, q>0$ e $\Gamma(\cdot)$ é a função gama, ou seja,

$$
\Gamma(p)=\int_{0}^{\infty} y^{p-1} e^{-y} d y .
$$

A média e a variância de $y$ são, respectivamente,

$$
E(y)=\frac{p}{p+q}
$$

$\mathrm{e}$

$$
\operatorname{var}(y)=\frac{p q}{(p+q)^{2}(p+q+1)}
$$

Ferrari e Cribari-Neto (2004) propuseram uma parametrização diferente, fazendo $\mu=\frac{p}{p+q}$ e $\phi=p+q$ :

$$
f(y ; \mu, \phi)=\frac{\Gamma(\phi)}{\Gamma(\mu \phi) \Gamma((1-\mu) \phi)} y^{\mu \phi-1}(1-y)^{(1-\mu) \phi-1}, 0<y<1,
$$

com $0<\mu<1$ e $\phi>0$. Dizemos que $y$ tem distribuição beta com média $\mu$ e precisão $\phi$, escrevendo-se $y \sim \beta(\mu, \phi)$. A Figura 1 apresenta densidades beta para diferentes combinações de $\mu$ e $\phi$. O parâmetro $\phi$ é conhecido como parâmetro de precisão, para $\mu$ fixo. Quanto maior o $\phi$, menor a variância de $y . \phi^{-1}$ é um parâmetro de dispersão. A média e a variância de $y$, nesse caso, são, respectivamente,

$$
E(y)=\mu
$$




$$
\operatorname{Var}(y)=\frac{\mu(1-\mu)}{1+\phi}
$$

Figura 1: Densidades beta para diferentes combinações de média e parâmetro de precisão $(\mu, \phi)$.

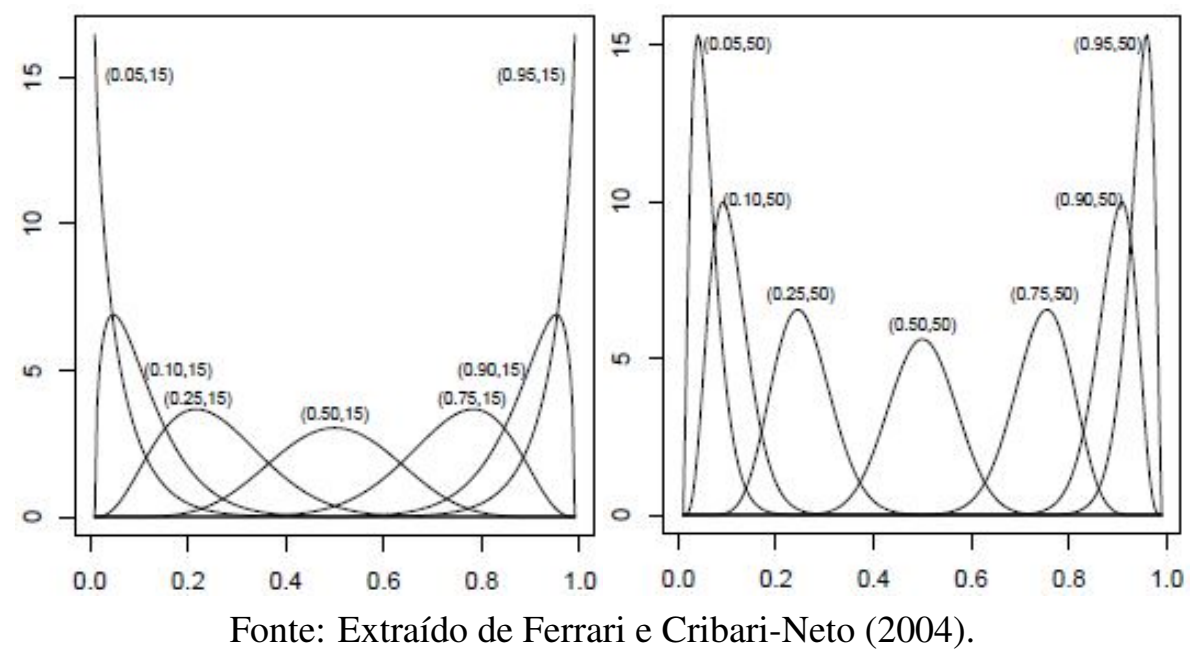

Considere $y_{1}, y_{2}, \ldots, y_{n}$ uma amostra aleatória tal que $y_{i} \sim \beta\left(\mu_{i}, \phi\right)$, com $i=1,2, \ldots, n$. O modelo de regressão beta é definido, portanto, como:

$$
g\left(\mu_{i}\right)=x_{i}^{T} \beta=\eta_{i}
$$

onde $\beta=\left(\beta_{1}, \beta_{2}, \ldots, \beta_{k}\right)^{T}$ é um vetor $k \times 1$ parâmetros de regressão desconhecidos $(k<n)$, $x_{i}=\left(x_{i 1}, x_{i 2}, \ldots, x_{i k}\right)^{T}$ é o vetor de $k$ variáveis independentes e $\eta_{i}$ é um preditor linear $\left(\eta_{i}=\right.$ $\beta_{1} x_{i 1}+\ldots+\beta_{k} x_{i k}$, normalmente $x_{i 1}=1$ para todo $i$, desde que o modelo tenha um intercepto). Importante salientar que $g(\cdot):(0,1) \mapsto \Re$ é uma função de ligação estritamente crescente e duas vezes diferenciável. Quando uma função de ligação é aplicada a $\mu$, ambos os lados da equação de regressão assumem valores na reta real. Além disso, há uma flexibilidade adicional, pois o pesquisador pode escolher a função que melhor se ajusta ao modelo. As funções de ligação mais usadas são:

- logit, $\operatorname{com} g(\mu)=\log [\mu /(1-\mu)]$;

- probit, com $g(\mu)=\Phi^{-1}(\mu)$, onde $\Phi(\cdot)$ é a função de distribuição normal padrão;

- $\log -\log , \operatorname{com} g(\mu)=-\log [-\log (\mu)]$;

- $\log$-log complementar, $\operatorname{com} g(\mu)=\log [-\log (1-\mu)]$; e

- Cauchy, $\operatorname{com} g(\mu)=\tan [\pi(\mu-0,5)]$.

O modelo de regressão beta proposto por Ferrari e Cribari-Neto (2004) assume que o parâmetro de precisão é constante, ou seja, a dispersão é constante para todas as observações. Simas et al. (2010) propuseram uma estrutura de regressão para o parâmetro de precisão, culminando no modelo de regressão beta com dispersão variável. Nesse modelo, o parâmetro de precisão é modelado de forma similar à media, ou seja, $y_{i} \sim \beta\left(\mu_{i}, \phi_{i}\right)$, com $i=1, \ldots, n \mathrm{e}$

$$
\begin{aligned}
& g_{1}\left(\mu_{i}\right)=\eta_{1 i}=x_{i}^{T} \beta \\
& g_{2}\left(\phi_{i}\right)=\eta_{2 i}=z_{i}^{T} \gamma
\end{aligned}
$$

onde $\beta=\left(\beta_{1}, \ldots, \beta_{k}\right)^{T}$ e $\gamma=\left(\gamma_{1}, \ldots, \gamma_{h}\right)^{T}$, com $k+h<n$, são vetores de parâmetros de regressão desconhecidos, $\eta_{1 i}$ e $\eta_{2 i}$ são preditores lineares e $x_{i}$ e $z_{i}$ são os vetores de regressão.

Em relação a $\phi$, pode-se utilizar a função logarítmica, $\operatorname{com} b(\phi)=\log (\phi)$, ou raíz quadrada, $\operatorname{com} b(\phi)=\sqrt{\phi}$. 


\subsection{Variáveis Selecionadas para o Modelo MDEA-Beta}

No primeiro estágio utilizou-se MDEA para levantamento dos escores de eficiência tributária municipal. Os inputs e outputs selecionados para o modelo encontram-se detalhados na Tabela 1. Foram definidas como inputs variáveis que representam a despesa total das secretarias de administração e finanças dos municípios paraibanos, empenhadas na função administração, e o número de servidores destas secretarias. Esses parâmetros representam a dimensão e o custo da administração fazendária municipal, refletindo diretamente no esforço fiscal dos municípios. Como outputs foram definidas variáveis que correspondem às receitas arrecadadas com IPTU (Imposto sobre propriedade predial e territorial urbana), IRRF (Imposto sobre renda e proventos de qualquer natureza retido na fonte), ITBI (Imposto sobre transmissão de bens imóveis), ISS (Imposto sobre serviços de qualquer natureza), taxas e contribuição de melhoria. Como output foi utilizada,ainda, a população estimada para 2015. Variáveis similares já foram utilizadas em outros trabalhos sobre mensuração de eficiência técnica tributária, a exemplo de Sousa et al. (2012).

Tabela 1: Inputs e outputs utilizados no modelo MDEA.

\begin{tabular}{|c|c|c|}
\hline Variável & Descrição & Média (Desvio Padrão) \\
\hline \multicolumn{3}{|l|}{ Inputs } \\
\hline$\overline{\operatorname{desp}}{ }^{*}$ & $\begin{array}{l}\text { Despesa total das secretarias de ad- } \\
\text { ministração e finanças dos municípios } \\
\text { empenhadas na função administração } \\
\text { durante o exercício de } 2015 \text { (em reais) }\end{array}$ & $1.926 .606,45(2.218 .944,48)$ \\
\hline $\operatorname{serv} v^{*}$ & $\begin{array}{l}\text { Número de servidores das secretarias } \\
\text { de administração e finanças dos muni- } \\
\text { cípios ao final do exercício de } 2015\end{array}$ & $40,67(44,56)$ \\
\hline \multicolumn{3}{|l|}{ Outputs } \\
\hline$\overline{i p t u^{*}}$ & $\begin{array}{l}\text { Receita de IPTU arrecadada em } 2015 \\
\text { (em reais) }\end{array}$ & $82.171,85(333.065,64)$ \\
\hline $\operatorname{irr} f^{*}$ & $\begin{array}{l}\text { Receita de IRRF arrecadada em } 2015 \\
\text { (em reais) }\end{array}$ & $320.245,82(598.105,47)$ \\
\hline$i t b i^{*}$ & $\begin{array}{l}\text { Receita de ITBI arrecadada em } 2015 \\
\text { (em reais) }\end{array}$ & $135.742,28(785.681,66)$ \\
\hline$i s s^{*}$ & $\begin{array}{l}\text { Receita de ISS arrecadada em } 2015 \\
\text { (em reais) }\end{array}$ & $574.691,46(1.551 .806,90)$ \\
\hline $\operatorname{taxm}^{*}$ & $\begin{array}{l}\text { Receitas de taxas e contribuição de me- } \\
\text { lhoria arrecadadas em } 2015 \text { (em reais) }\end{array}$ & $77.640,93(251.469,34)$ \\
\hline pop $^{* *}$ & Estimativa da população em 2015 & $12.936,72(16.475,97)$ \\
\hline
\end{tabular}

Nos modelos de regressão foram utilizados como variável dependente os escores de eficiência calculados no primeiro estágio. Como variáveis explicativas foram utilizados indicadores socioeconômicos, fiscais, operacionais e geográficos, que poderiam ter influência na eficiência tributária dos municípios analisados, e que foram utilizadas em estudos anteriores. As variáveis encontram-se detalhadas na Tabela 2.

\section{Resultados}

Nesta seção são apresentados os resultados empíricos obtidos para 210 municípios do Estado da Paraíba, a partir da implementação do modelo MDEA-beta. Os escores de eficiência foram calculados com base no método MDEA, desenvolvido por Stosic e Fittipaldi (2007). O modelo de regressão linear estimado pelo método dos mínimos quadrados ordinários e o modelo de regressão beta foram implementados no software livre R. A regressão beta foi estimada com uso do pacote betareg, implementado por Cribari-Neto e Zeileis (2009). Como apresentado nas Tabelas 1 e 2 , foram utilizados dados de 2015 , com exceção das informações relativas ao valor adicionado 
ao PIB pelo setor industrial, disponibilizadas pelo IBGE apenas para 2013. Na Seção 4.1 serão apresentados os resultados obtidos no primeiro estágio. Em seguida, serão descritos os resultados obtidos e as análises de diagnóstico para os modelos de regressão.

Tabela 2: Variáveis do $2^{\circ}$ estágio - Regressão linear estimada pelo método dos mínimos quadrados ordinários e regressão beta.

\begin{tabular}{|c|c|c|}
\hline Variáveis contínuas & Descrição & Média (Desvio Padrão) \\
\hline$m d e a^{* * *}$ & $\begin{array}{l}\text { Escores de eficiência calculados pela } \\
\text { metodologia MDEA }\end{array}$ & $0,236(0,150)$ \\
\hline auto* & $\begin{array}{l}\text { Razão entre a receita tributária arreca- } \\
\text { dada e a receita corrente total dos mu- } \\
\text { nicípios de } 2015\end{array}$ & $0,028(0,027)$ \\
\hline depfpms* & $\begin{array}{l}\text { Razão entre a soma das parcelas do } \\
\text { FPM e do ICMS recebidas e a receita } \\
\text { corrente total dos municípios de } 2015\end{array}$ & $0,571(0,116)$ \\
\hline receitapc* & $\begin{array}{l}\text { Receita corrente per capita no exercí- } \\
\text { cio de } 2015 \text { (reais) }\end{array}$ & $2.518,78(918,71)$ \\
\hline pibind $^{* *}$ & $\begin{array}{l}\text { Valor adicionado ao PIB pelo setor in- } \\
\text { dustrial no exercício de } 2013 \text { (mil re- } \\
\text { ais) }\end{array}$ & $14.851,02(56.813,98)$ \\
\hline herfindahl $l^{* * *}$ & $\begin{array}{l}\text { Índice de concentração de Herfindahl } \\
\text { aplicado aos tributos municipais arre- } \\
\text { cadados em } 2015\end{array}$ & $0,432(0,103)$ \\
\hline transp ${ }^{*}$ & $\begin{array}{l}\text { Índice de transparência dos municípios } \\
\text { em novembro de } 2015 \text { (variando de } 0 \text { a } \\
\text { 10) }\end{array}$ & $6,200(1,005)$ \\
\hline Variáveis dummy & Descrição & Frequência (\%) \\
\hline d_cadiptu** & $\begin{array}{l}1 \text { se o município possui cadastro infor- } \\
\text { matizado de contribuintes do IPTU e } 0 \\
\text { caso contrário }\end{array}$ & $138(65,71)$ \\
\hline$d_{-}$litoral ${ }^{* *}$ & $\begin{array}{l}1 \text { se o município pertence à mesorre- } \\
\text { gião do Litoral e } 0 \text { caso contrário }\end{array}$ & $27(12,86)$ \\
\hline d_borborema ${ }^{* *}$ & $\begin{array}{l}1 \text { se o município pertence à mesorre- } \\
\text { gião da Borborema e } 0 \text { caso contrário }\end{array}$ & $39(18,57)$ \\
\hline$d \_s e r t a o^{* *}$ & $\begin{array}{l}1 \text { se o município pertence à mesorre- } \\
\text { gião do Sertão e } 0 \text { caso contrário }\end{array}$ & $79(37,62)$ \\
\hline d_pop $10000^{* *}$ & $\begin{array}{l}1 \text { se o município possui menos de } \\
10.000 \text { habitantes e } 0 \text { caso contrário }\end{array}$ & $125(59,52)$ \\
\hline
\end{tabular}

Fonte: Elaborada pelos autores.

\section{1. $1^{\circ}$ Estágio - MDEA}

No primeiro estágio foram obtidos os escores de eficiência MDEA a partir dos inputs e outputs discriminados na Tabela 1. De acordo com a Tabela 3, as medidas descritivas dos escores de eficiência apresentam valor mínimo de 0,029, correspondente ao Município de Sossêgo, e máximo de 0,818 , correspondente ao Município de Cabedelo. A média dos municípios do Estado da Paraíba alcançou o valor de 0,236 , superior à mediana $(0,196)$, indicando uma tendência de assimetria na distribuição. O terceiro quartil apresentou valor de 0,288 , o que caracteriza uma predominância de nível reduzido de eficiência tributária, resultado que se alinha ao obtido por Campello (2003).

Esse aspecto pode ser visualizado no histograma da distribuição dos escores de eficiência e no gráfico boxplot, Figura 2. Quanto aos testes de assimetria e curtose, realizados com o uso do pacote fBasics do software R, verifica-se que a distribuição é leptocúrtica $(3,095)$ e apresenta assimetria à direita $(1,690)$. 
Tabela 3: Medidas descritivas dos escores de eficiência MDEA.

\begin{tabular}{lcccccc}
\hline Variável & Mínimo & $Q_{1 / 4}$ & Mediana & Média & $Q_{3 / 4}$ & Máximo \\
\hline mdea & 0,029 & 0,136 & 0,196 & 0,236 & 0,288 & 0,818 \\
\hline
\end{tabular}

Fonte: Elaborada pelos autores.

Figura 2: Gráficos dos escores de eficiência MDEA (histograma e boxplot).
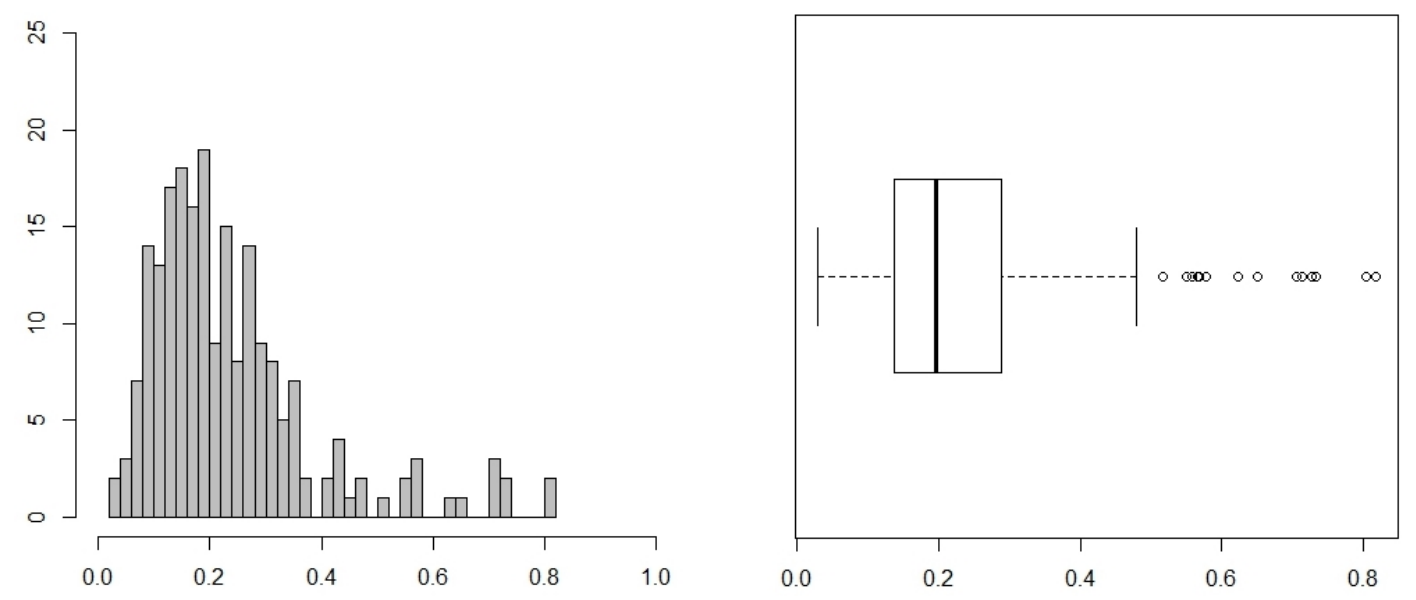

Fonte: Elaborada pelos autores.

Médias dos escores de eficiência foram obtidas, ainda, por faixa de população. Os municípios foram distribuídos em quatro categorias. Observou-se que a média aumenta de acordo com o aumento na população, ou seja, municípios mais populosos tendem a ser mais eficientes. Pode-se deduzir que esses municípios possuem maior dinamismo econômico, o que pode refletir no aperfeiçoamento da estrutura de arrecadação tributária. A Tabela 4 apresenta os resultados alcançados.

Tabela 4: Média dos escores de eficiência MDEA por faixa de população.

\begin{tabular}{lcc}
\hline População & Frequência $(\%)$ & Média (Desvio Padrão) \\
\hline 0 a 10.000 habitantes & 59,52 & $0,167(0,079)$ \\
10.000 a 20.000 habitantes & 25,71 & $0,297(0,134)$ \\
20.000 a 50.000 habitantes & 10,95 & $0,353(0,174)$ \\
Acima de 50.000 habitantes & 3,82 & $0,559(0,232)$ \\
\hline
\end{tabular}

Fonte: Elaborada pelos autores.

Verifica-se que cerca de 59,52\% dos municípios analisados possuem população abaixo de dez mil habitantes. Esses entes alcançaram a menor média nos escores de eficiência tributária $(0,167)$. Por outro lado, os municípios que possuem maior média, com população acima de cinquenta mil habitantes, representam apenas 3,82\% dos municípios do Estado da Paraíba, tendo alcançado a maior média $(0,559)$. A Figura 3 apresenta a distribuição geográfica dos escores de eficiência tributária municipal no Estado da Paraíba. 
Figura 3: Distribuição dos escores de eficiência no Estado da Paraíba.

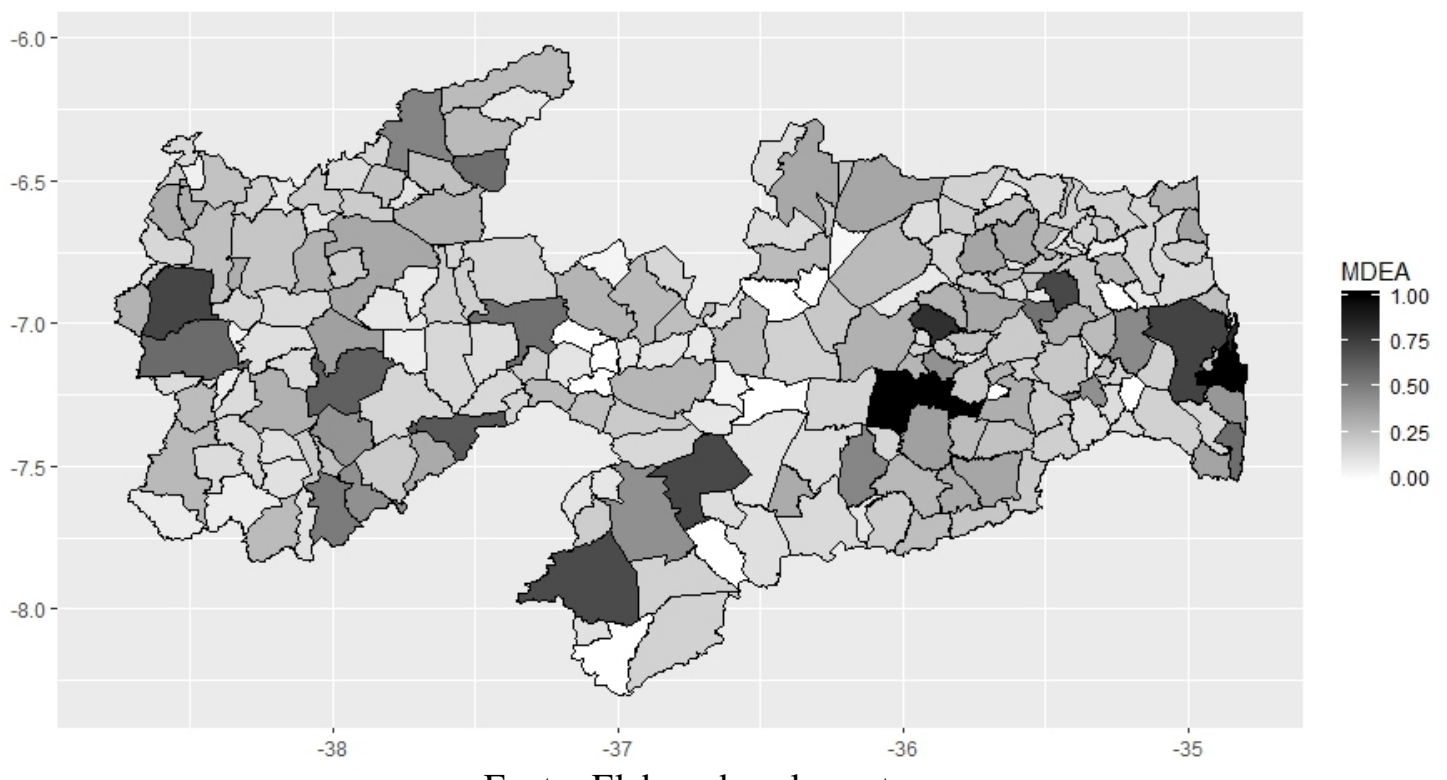

Fonte: Elaborada pelos autores.

\section{2. $2^{\circ}$ Estágio - Regressão Beta e Regressão Linear Estimada pelo Método dos Mínimos Quadrados Ordinários}

Nesta seção são apresentados os resultados obtidos no segundo estágio. No intuito de levantar os determinantes dos escores de eficiência tributária dos 210 municípios pesquisados, foi realizada análise de regressão para verificar a relação entre a variável resposta e as variáveis explicativas. Foram estimados parâmetros utilizando-se regressão beta com dispersão constante e com dispersão variável. Foi utilizado, também, um modelo de regressão linear estimado pelo método dos mínimos quadrados ordinários. Em seguida, foram realizados testes de diagnóstico aplicados ao modelo de regressão beta com dispersão variável. Não foi constatada correlação significativa nas variáveis que integram os modelos de regressão.

$\mathrm{O}$ modelo de regressão beta mostra-se apropriado para modelagem de dados restritos ao intervalo $(0,1)$. Adicionalmente, o modelo é heteroscedástico e facilmente acomoda assimetrias que são características comumente observadas em dados que assumem valores no intervalo unitário padrão (Pereira et al., 2014). A variável mdea é restrita ao intervalo mencionado, além de possuir distribuição assimétrica. Optou-se, com isso, pela utilização do modelo de regressão beta proposto por Ferrari e Cribari-Neto (2004). Foi utilizado, ainda, o modelo de regressão beta com dispersão variável, proposto por Simas et al. (2010), com a introdução de uma estrutura de regressão para o parâmetro de precisão $\phi$. A Tabela 5 apresenta as estimativas dos parâmetros para os modelos de regressão beta com dispersão constante e com dispersão variável. Foi empregada, ainda, regressão linear estimada pelo método dos mínimos quadrados ordinários, no intuito de evidenciar o poder de ajuste que o modelo de regressão beta proporciona quando aplicado a escores de eficiência.

A análise de regressão linear estimada pelo método dos mínimos quadrados ordinários apresentou $R^{2}$ no valor de 0,629 e p-valor da Estatística $\mathrm{F}$ tendendo a zero $\left(<2,2 \times 10^{-16}\right)$, rejeitandose a hipótese nula de não significância geral da regressão. As variáveis auto, depfpms, pibind, herfindahl, d_borborema, d_sertao e $d \_p o p 10000$ foram significativas ao nível de $5 \%$. Os resultados indicam que as variáveis auto, pibind, d_borborema e $d \_s e r t a o$ têm influência positiva sobre a eficiência tributária dos municípios analisados. As variáveis depfpms, herfindahl e d_pop10000 têm influência negativa. O teste de Breusch-Pagan apresentou valor de 26, 463 e p-valor igual a 0,005534, rejeitando-se a hipótese nula de homocedasticidade. Os indícios de presença de hete- 
rocedasticidade reforçam a hipótese de adequação do modelo de regressão beta para verificar a relação existente entre os escores de eficiência tributária e seus determinantes.

O modelo de regressão beta com dispersão constante e função de ligação default (logit) apresentou Pseudo- $R^{2}$ no valor de 0,6474 . Nesse modelo, foram significativas, ao nível de $5 \%$, as seguintes variáveis: auto, depfpms, receitapc, pibind, herfindahl, d_borborema e d_sertao. Os resultados indicam que as variáveis auto, pibind, $d \_b o r b o r e m a$ e $d \_s e r t a o$ têm influência positiva sobre a eficiência tributária dos municípios analisados. As variáveis depfpms, receitapc e herfindahl têm influência negativa. O teste Reset apresentou p-valor de 0,7863 , rejeitando-se a hipótese nula de má especificação do modelo.

O modelo de regressão beta com dispersão variável apresentou resultados mais significativos com a utilização da função de ligação probit. A estrutura de regressão do parâmetro de precisão $\phi$ foi testada por meio dos métodos forward e backward, apresentando melhores resultados a estrutura formada apenas pela variável depfpms. Os resultados da regressão apresentam Pseudo- $R^{2}$ no valor de 0,6462 . Nesse modelo, foram significativas, ao nível de $5 \%$, as seguintes variáveis: auto, depfpms, receitapc, pibind, herfindahl, transp, d_cadiptu,d_borborema,d_sertao e $d \_p o p 10000$. Os resultados indicam que as variáveis auto, pibind, transp, d_borborema e $d_{-}-$ sertao têm influência positiva sobre a eficiência tributária dos municípios analisados. As variáveis depfpms, receitapc, herfindahl, d_cadiptu e d_pop10000 têm influência negativa. O teste Reset apresentou p-valor de 0,101 , rejeitando-se a hipótese nula de má especificação do modelo.

Foi aplicado o critério de seleção de modelos sugerido por Akaike para comparar os modelos de regressão beta com dispersão constante e com dispersão variável, obtendo-se os valores de $-448,60$ e $-477,23$, respectivamente. Os modelos foram submetidos, ainda, ao teste de razão de verossimilhança, obtendo-se p-valor de $3,116 \times 10^{-8}$, e ao teste de Wald, cujo resultado apresentou p-valor menor que $2,2 \times 10^{-16}$. Conclui-se, com isso, que o modelo com dispersão variável está mais bem especificado.

A Figura 4 trata da análise dos resíduos para os modelos de regressão beta com dispersão constante e com dispersão variável. São apresentados os gráficos dos resíduos versus índices de observações, da distância de Cook e da semi-normal dos resíduos. Em estatística, a distância de Cook é uma medida da influência de uma observação ao realizar-se uma análise de regressão por mínimos quadrados. O nome é uma homenagem ao estatístico americano R. Dennis Cook. A distância de Cook mede o efeito de excluir uma dada observação. O uso da distância de Cook no presente trabalho tem a finalidade de verificar a qualidade de ajuste do modelo de regressão beta. Foi constatado que o modelo com dispersão variável apresenta maior qualidade no ajuste quando comparado ao modelo com dispersão constante. Verifica-se nos gráficos (Figuras 4.c e 4.d) que duas observações apresentaram comportamento atípico em relação às demais, correspondendo aos Municípios de Santa Rita (observação 161) e São José de Piranhas (observação 177). No entanto, as observações encontram-se dentro do limite aceitável em regras operacionais para distância de Cook, ou seja, valores menores que 1 .

Após a apresentação das estimativas dos modelos de regressão, passemos à discussão dos resultados obtidos para o modelo de regressão beta com dispersão variável, modelo que apresentou resultados mais favoráveis em termos de significância e magnitude dos parâmetros. 


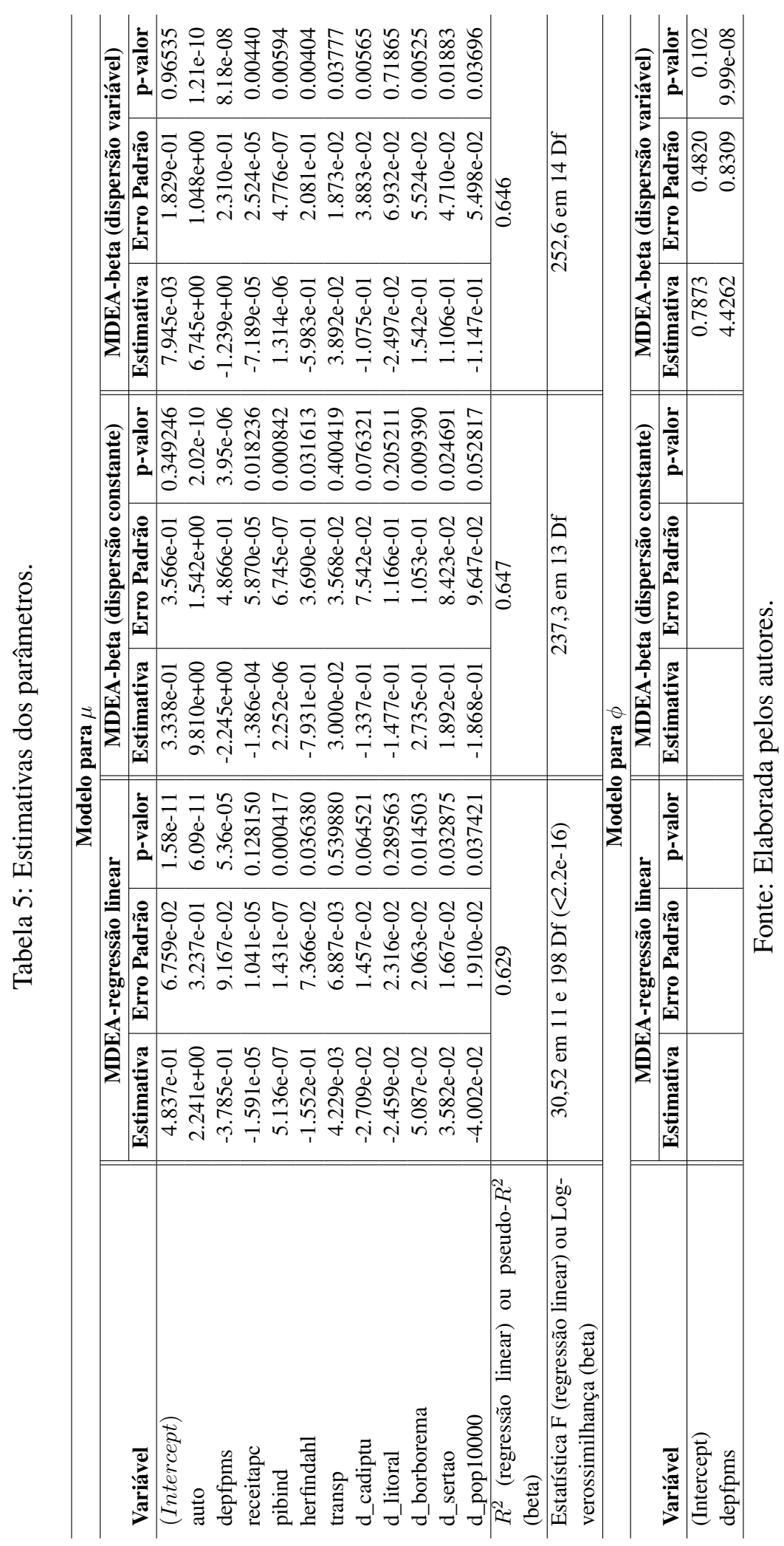


A variável auto, que representa a autossuficiência financeira do município, calculada pela razão entre a receita tributária arrecadada e a receita corrente total, apresentou influência positiva sobre os escores de eficiência tributária. Segundo Lima e Diniz (2016), é um indicador que reflete a capacidade de gerar receita própria, por revelar o esforço do governo local em produzir receitas, contando com a base econômica da comunidade. É um importante indicador da eficiência da administração tributária. De acordo com Boetti et al. (2012), essa variável pode ser interpretada também como uma medida do VFI (Vertical Fiscal Imbalance), ou seja, do grau de descentralização político-administrativa aplicada aos municípios analisados. A sugestão é que municípios que apresentam maior esforço fiscal tendem a ser mais eficientes. Essa conclusão alinha-se aos resultados obtidos por Sousa et al. (2012).

A variável pibind, que representa o valor adicionado ao PIB pelo setor industrial, também apresentou relação direta com a eficiência tributária. Os resultados indicam que municípios mais industrializados tendem a ser mais eficientes, guardando coerência com os resultados apresentados por Sousa et al. (2012) e Pereira et al. (2014).

Apresentou influência positiva, também, a variável transp, que reflete o grau de accountability dos governos locais, por meio da divulgação, em meios de acesso público, das informações sobre a gestão orçamentária, financeira, patrimonial, dentre outras. Os resultados indicam que municípios mais transparentes tendem a ser mais eficientes.

Os resultados estimados para as variáveis $d \_$borborema e $d \_s e r t a o$ sugerem que os municípios localizados nas mesorregiões da Borborema e do Sertão tendem a ter sistemas de administração tributária mais eficientes, quando comparados às outras mesorregiões.

Os resultados mostram que a variável depfpms, que representa a dependência de transferências constitucionais pelos municípios, constituída pela razão entre a soma da cota-parte do FPM (Fundo de Participação dos Municípios) com a cota-parte do ICMS (Imposto sobre circulação de mercadorias e serviços) e a receita corrente total, contribuiu para a redução da eficiência tributária municipal. As estimativas indicam que municípios mais dependentes tendem a exercer menor esforço fiscal na arrecadação dos tributos de sua competência. Esse resultado alinha-se ao proposto por Campello (2003), Gasparini e Melo (2004), Orair e Alencar (2010) e Sousa et al. (2012).

A variável receitapc, que representa a receita corrente per capita, constitui um fator de escala financeira dos municípios. As estimativas indicam uma influência negativa sobre a eficiência tributária, o que a princípio pode parecer controversa em relação ao resultado esperado. No entanto, para a maioria dos municípios do Estado da Paraíba, a receita de transferências constitui parcela majoritária da receita corrente, exercendo maior influência sobre os escores de eficiência quando comparada à receita tributária arrecadada.

Apresentou, também, influência negativa sobre a eficiência tributária a variável herfindahl, que representa o índice de concentração de Herfindahl aplicado aos tributos municipais. As estimativas sugerem que, quanto mais concentrada é a arrecadação, menor é a eficiência. Uma maior diversificação traria, portanto, resultados mais favoráveis. Esse resultado é coerente com o obtido por Sousa et al. (2012).

A variável d_cadiptu, que representa a existência ou não de cadastro informatizado de contribuintes do IPTU (Imposto sobre propriedade predial e territorial urbana), também apresentou influência negativa sobre os escores de eficiência tributária. Esse resultado diverge do esperado, pois presume-se que uma maior modernização dos serviços fazendários traga reflexos positivos sobre a eficiência na arrecadação. Uma hipótese que pode justificar esse resultado controverso é o desinteresse do gestor na efetiva cobrança de IPTU, por questões políticas. O fator político é uma variável omitida do modelo que pode ter um papel importante na eficiência tributária. Logo, municípios de pequeno porte tenderiam a possuir menor arrecadação própria devido à proximidade entre eleitores e políticos.

Por fim, os resultados estimados para a variável d_pop10000 indicam que municípios com população abaixo de dez mil habitantes tendem a ser menos eficientes na arrecadação dos tributos de sua competência. 
Figura 4: Resíduos versus índices de observações (a) e (b); distância de Cook (c) e (d); e semi-normal dos resíduos (e) e (f).

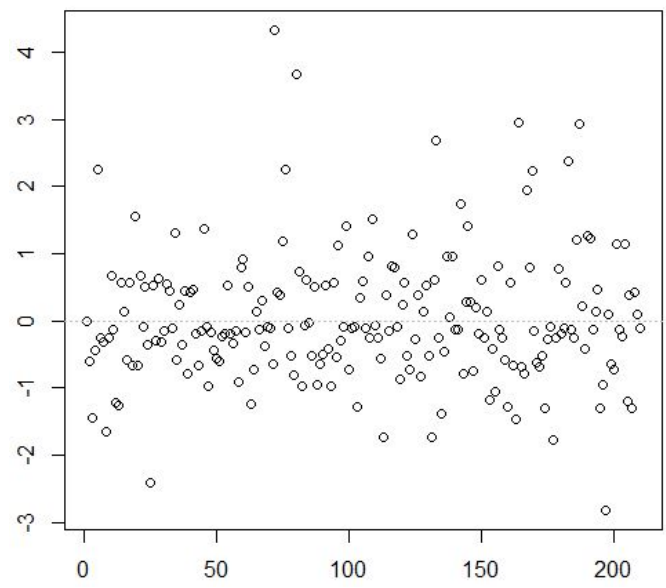

(a) Dispersão constante

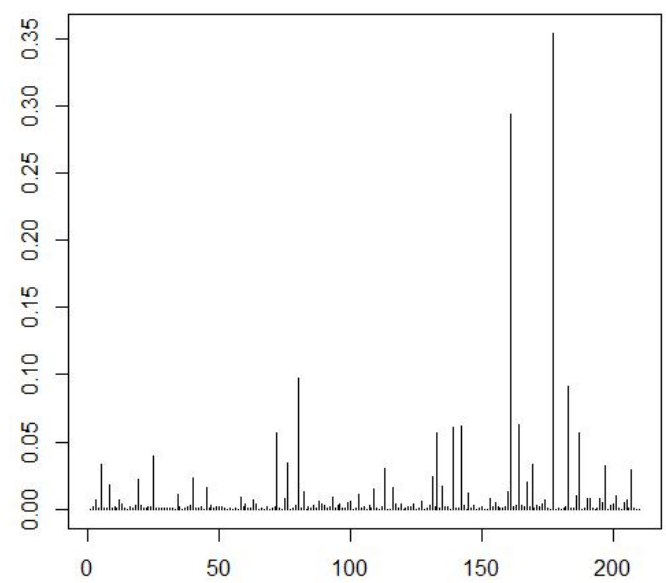

(c) Dispersão constante

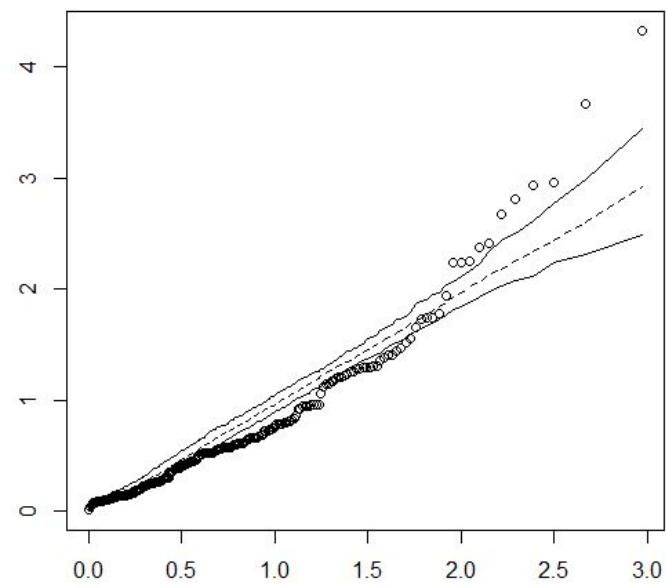

(e) Dispersão constante

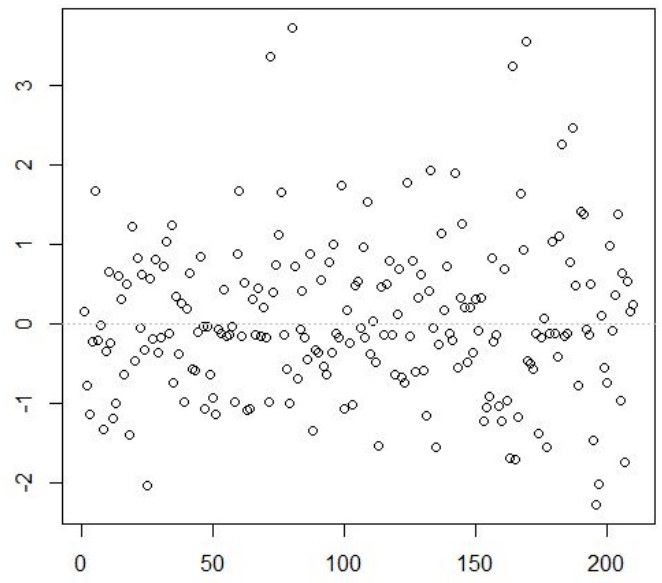

(b) Dispersão variável

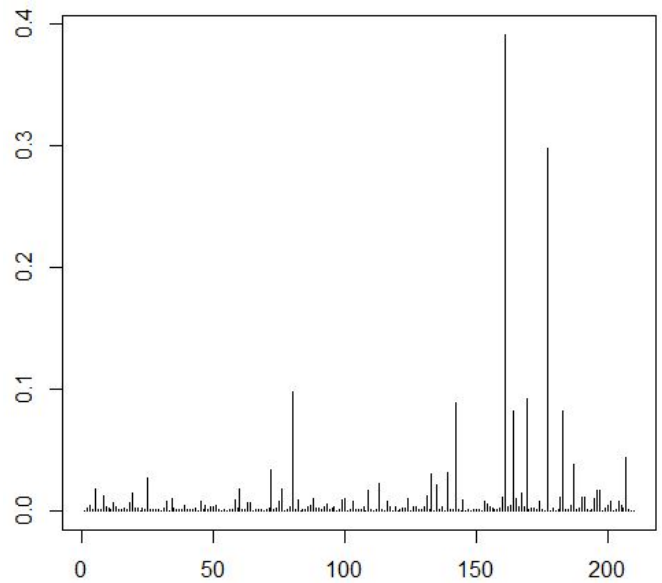

(d) Dispersão variável

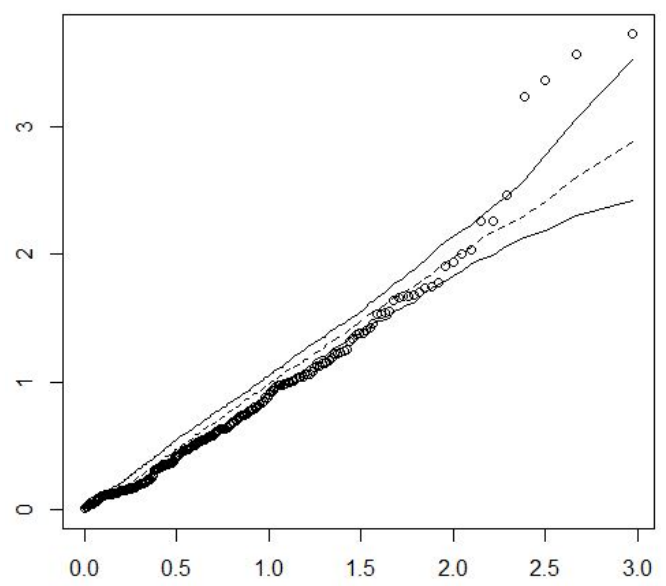

(f) Dispersão variável

Fonte: Elaborada pelos autores.

\section{Conclusão}

A presente pesquisa avaliou a eficiência técnica tributária de 210 municípios do Estado da Paraíba e seus determinantes, por meio de abordagem semi-paramétrica em dois estágios. No pri- 
meiro estágio, foram calculados escores de eficiência com uso do MDEA. Um aspecto positivo nesta etapa foi a disponibilidade de dados sobre as variáveis utilizadas como insumos e produtos. O Sistema SAGRES, do Tribunal de Contas do Estado da Paraíba, permitiu acesso à base de dados de 2015 em um nível apropriado de detalhamento das informações. Foi possível restringir os insumos à despesa e ao número de servidores das secretarias de administração e finanças dos municípios, considerando apenas a função administração, o que possibitou maior aproximação com a realidade da administração municipal e, consequentemente, maior precisão no cálculo dos escores de eficiência. Quanto aos resultados do $1^{\mathrm{O}}$ estágio, os escores de eficiência apresentaram média de 0,236 , nível considerado baixo, mantendo-se nesse patamar até o terceiro quartil $(0,288)$. Observou-se, ainda, que os níveis de eficiência estão diretamente relacionados com a população dos municípios. Municípios com menor número de habitantes apresentaram níveis mais reduzidos de eficiência tributária. Cerca de 96,18\% dos municípios apresentaram escores de eficiência abaixo de 0,353 .

No segundo estágio, foram estimados parâmetros para análise dos determinantes dos escores de eficiência tributária por meio de análise de regressão. Foram utilizados os modelos de regressão linear estimado pelo método dos mínimos quadrados ordinários, regressão beta com dispersão constante e regressão beta com dispersão variável. Na explicação dos escores de eficiência foram consideradas variáveis socioeconômicas, fiscais, operacionais e geográficas, obtidas das bases de dados do IBGE e do Tribunal de Contas do Estado da Paraíba. Os resultados indicam que os modelos empregados apresentaram resultados coerentes. No entanto, o modelo de regressão beta com dispersão variável apresentou maior qualidade de ajuste aos dados, como constatado pelos testes de especificação, refletindo-se em variáveis com maior magnitude e mais significativas. Uma vantagem do uso do modelo MDEA-beta foi o fato de que, neste caso, o resultado do cálculo dos escores de eficiência MDEA estão situados no intervalo aberto $(0,1)$, adequando-se ao modelo de regressão beta padrão. Com isso, não houve necessidade de utilização de modelos mais sofisticados, como o modelo de regressão beta inflacionado. A análise dos resíduos apresentou resultados adequados à proposta da presente pesquisa, considerando o trade-off característico entre qualidade do ajustamento e sua complexidade.

Quanto à interpretação dos resultados apresentados pelo modelo MDEA-beta, no que se refere à eficiência tributária, verifica-se que:

- Municípios que apresentam maior grau de descentralização (VFI), ou maior esforço fiscal, tendem a ser mais eficientes;

- Municípios mais dependentes de transferências constitucionais tendem a exercer menor esforço fiscal na arrecadação dos tributos de sua competência, resultando em uma menor eficiência;

- Municípios mais industrializados tendem a ser mais eficientes;

- Municípios com maior grau de accountability, ou seja, com gestão mais transparente, tendem a ser mais eficientes;

- Municípios localizados nas mesorregiões da Borborema e do Sertão tendem a ser mais eficientes, quando comparados às outras mesorregiões;

- Municípios com maior receita per capita tendem a ser menos eficientes (o que a princípio pode parecer controverso em relação ao resultado esperado. No entanto, para a maioria dos municípios do Estado da Paraíba, a receita de transferências constitui parcela majoritária da receita corrente, exercendo maior influência sobre os escores de eficiência quando comparada à receita tributária arrecadada);

- Municípios com maior concentração na arrecadação de tributos tendem a ser menos eficientes. Uma maior diversificação traria, portanto, resultados mais favoráveis;

- Municípios que possuem cadastro informatizado de contribuintes de IPTU (Imposto sobre propriedade predial e territorial urbana) tendem a ser menos eficientes (esse resultado diverge do esperado, pois presume-se que uma maior modernização dos serviços fazendários traga reflexos positivos sobre a eficiência na arrecadação. Uma hipótese que pode justifi- 
car esse resultado controverso pode ter relação com um possível desinteresse do gestor na efetiva cobrança de IPTU);

- Municípios de menor população, ou seja, de menor dimensão socioeconômica, tendem a ser menos eficientes.

Conclui-se, portanto, que os escores de eficiência tributária municipal servem como indicadores relevantes para avaliação do sistema de arrecadação de receitas de competência dos municípios. Além disso, os parâmetros estimados no modelo de regressão beta acrescentam informações importantes para compreensão da administração tributária municipal. Um aspecto a ser observado foi a ausência no modelo de regressão de fator que reflita possível interdependência espacial existente nos dados. Sugere-se que em estudos posteriores seja considerada a possibilidade de utilização de modelo de regressão beta que incorpore um componente espacial.

Agradecimentos. Os autores agradecem o apoio do Tribunal de Contas do Estado da Paraíba.

\section{Referências}

Banker, R. D., Charnes, A., e Cooper, W. W. Some models for estimating technical and scale inefficiencies in data envelopment analysis. Management Science, v. 30, n. 9, p. 1078-1092, 1984.

Bayer, F. M. Modelagem e inferência em regressão beta. Tese de Doutorado. Universidade Federal de Pernambuco, Recife - PE, 2011.

Boetti, L., Piacenza, M., e Turati, G. Decentralization and local governments' performance: how does fiscal autonomy affect spending efficiency? FinanzArchiv: Public Finance Analysis, v. 68, n. 3, p. 269-302, 2012.

Campello, C. Eficiência municipal: um estudo no Estado de São Paulo. Tese de Doutorado. Programa de Pós-Graduação em Administração, Departamento de Administração, Faculdade de Economia, Administração e Contabilidade da Universidade de São Paulo - SP, 2003.

Charnes, A., Cooper, W. W., e Rhodes, E. Measuring efficiency of decision making units. European Journal of Operational Research, v. 1, p. 429-44, 1978.

Cribari-Neto, F. e Pereira, T. Avaliação da eficiência de administrações municipais no Estado de São Paulo: uma nova abordagem via modelos de regressão beta. Revista Brasileira de Biometria, v. 31, p. 270-294, 2013.

Cribari-Neto, F. e Zeileis, A. Beta regression in r. Department of Statistics and Mathematics, WU Vienna University of Economics and Business, v. 1, 2009.

Farrell, M. J. The measurement of productive efficiency. Journal of the Royal Statistical Society. Series A (General), v. 120, n. 3, p. 253-290, 1957.

Feofiloff, P. Algoritmos em linguagem C. Rio de Janeiro - RJ: Elsevier Brasil, 2009.

Ferrari, S. e Cribari-Neto, F. Beta regression for modelling rates and proportions. Journal of Applied Statistics, v. 31, n. 7, p. 799-815, 2004.

Gasparini, C. E. e Melo, C. S. L. Equidade e eficiência municipal: uma avaliação do fundo de participação dos municípios-fpm. Finanças públicas. Brasília: Editora Universidade de Brasília, v. 8, p. 337-401, 2004.

Hindriks, J. e Myles, G. D. Intermediate public economics. Cambridge: MIT press, 2013. 
Lima, S. C. e Diniz, J. A. Contabilidade pública: análise financeira governamental. São Paulo: Atlas, 2016.

McDonald, J. Using least squares and tobit in second stage DEA efficiency analyses. European Journal of Operational Research, v. 197, n. 2, p. 792-798, 2009.

Orair, R. O. e Alencar, A. Esforço fiscal dos municípios: indicadores de condicionalidades para o sistema de transferências intergovernamentais. Monografia premiada no Prêmio Tesouro Nacional, v. 1, 2010.

Pereira, T. L., Souza, T. C., e Cribari-Neto, F. Uma avaliação da eficiência do gasto público nas regiões do brasil. Ciência e Natura, v. 36, p. 23-36, 2014.

Ribeiro, D. e Sousa, M. C. S. Jackstrapping DEA scores for robust efficiency measurement. In: Econometric Society 2004 Latin American Meetings. Number 217. Number 217. Econometric Society, 2004.

Simar, L. e Wilson, P. W. Estimation and inference in two-stage, semi-parametric models of production processes. Journal of Econometrics, v. 136, n. 1, p. 31-64, 2007.

Simas, A. B., Barreto-Souza, W., e Rocha, A. V. Improved estimators for a general class of beta regression models. Computational Statistics \& Data Analysis, v. 54, n. 2, p. 348-366, 2010.

Sousa, M. C. S. Mensurando a eficiência da atenção primária à saúde em presença de outliers e fatores exógenos: uma análise em dois estágios. Tese (Professor Titular), Departamento de Economia, Universidade Federal da Paraíba, v. 1, 2011.

Sousa, M. C. S., Araújo, P. L. C. P., e Tannuri-Pianto, M. E. Residual and technical tax efficiency scores for brazilian municipalities: a two-stage approach. Estudos Econômicos (São Paulo), v. 42, n. 1, p. 43-74, 2012.

Sousa, M. C. S. e Stosic, B. Technical efficiency of the brazilian municipalities: correcting nonparametric frontier measurements for outliers. Journal of Productivity Analysis, v. 24, n. 2, p. 157-181, 2005.

Stosic, B. D. e Fittipaldi, I. P. Multiple data envelopment analysis: The blessing of dimensionality. In: 5th International Symposium on DEA, Hyderabad. Hyderabad. Citeseer, 2007. 